\section{Similar risk of cancer in patients younger than 55 years with or without a total hip arthroplasty (THA): a popula- tion-based cohort study on 18,771 exposed to THA and 87,683 controls}

\author{
Yasmin D HAILER ${ }^{1}$, Johan KÄRRHOLM ${ }^{2,3}$, Niclas ERIKSSON ${ }^{4}$, Lars HOLMBERG ${ }^{5,6}$, \\ and Nils $P$ HAILER ${ }^{1,2}$
}

\author{
${ }^{1}$ Section of Orthopaedics, Department of Surgical Sciences, Uppsala University Hospital, Sweden; ${ }^{2}$ Swedish Arthroplasty \\ Register, Gothenburg, Sweden; ${ }^{3}$ Department of Orthopaedics, Institute of Clinical Sciences, The Sahlgrenska Academy, \\ University of Gothenburg, Sweden; ${ }^{4}$ Uppsala Clinical Research Center, Uppsala, Sweden; ${ }^{5}$ Department of Surgical Sciences, \\ Uppsala University Hospital, Sweden; ${ }^{6}$ King's College London, School of Cancer and Pharmaceutical Sciences, Translational \\ Oncology \& Urology Research (TOUR), London, UK \\ Correspondence: yasmin.hailer@surgsci.uu.se \\ Submitted 2021-10-08. Accepted 2022-01-11.
}

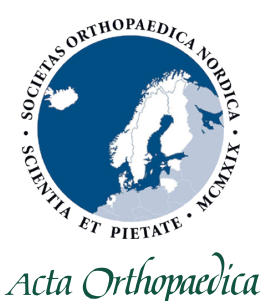

Background and purpose - Concerns related to a potentially increased risk of cancer after total hip arthroplasty (THA) have frequently surfaced, especially since the novel EU medical device regulation classified cobalt as carcinogenic. We assessed the risk of cancer after THA in a nationwide cohort of patients younger than 55 years at surgery.

Patients and methods - In this population-based longitudinal cohort study, 18,771 individuals exposed to THA were identified in the Swedish Hip Arthroplasty Registry (SHAR) and compared with 87,683 unexposed individuals who were matched by age, sex, and residence. Diagnoses, socioeconomic background, and dates of death were obtained from the Swedish Cancer Register, the National Patient Register, and Statistics Sweden. Primary outcome was the adjusted risk of any cancer after the first THA; secondary outcomes were specific cancer forms.

Results - We found no enhanced adjusted risk of developing any cancer, either in exposed females compared with unexposed females (hazard ratio [HR] 1.1, 95\% confidence interval [CI] 0.95-1.2), or in exposed males (HR 1.1, CI 0.99-1.2). When analysing specific cancers, increased adjusted risks were found for thyroid and pancreas cancer in exposed females, and for cancer of the stomach, skin melanoma, and prostate cancer in exposed males.

Interpretation - This study indicates that there is no statistically significant increased overall risk of cancer in young THA-exposed patients. The potentially slightly enhanced risk for specific cancers may be due to residual confounding resulting from risk factors not accounted for and merits further investigation.
Although THA surgery is generally considered a both safe and efficient intervention, concerns around a potentially increased risk of cancer have been raised repeatedly (1-3). THA implants release cobalt, chromium, and nickel ions or nanoparticles, which may have cancerogenic effects, and the Medical Device Regulation issued by the European Union classifies cobalt as a carcinogenic substance (4-6). Low concentrations of these metals are found after both cemented and cementless THA with conventional metal-on-polyethylene bearings, and even higher concentrations can be measured in tissues and blood of patients with large metal-on-metal bearings $(7,8)$. Metal ions may cause chromosomal aberrations in both peripheral blood and bone marrow of patients with THA $(9,10)$. Additionally, cemented THA exposes patients to the potentially toxic polymer polymethyl-methacrylate with various additives constituting the bone cement used to fix THA implants to bone.

Observational studies show small increases in the risk of developing hematological or lymphatic malignancies $(\mathbf{1}, \mathbf{1 1}, \mathbf{1 2})$ and an enhanced incidence of solid tumors in the prostate or skin after THA or knee arthroplasty (13-17), but these findings are contradicted by others $(\mathbf{1 4 , 1 7 - 1 9 )}$. Most of the cited studies base their findings on "average" THA populations with a mean age between 60 and 70 years at the time of surgery, but none specifically addresses the cancer risk in younger THA patients who are exposed to their implants and potentially toxic derivatives for much longer periods of time than elderly patients.

We therefore explored the risk of cancer in patients younger than 55 years at the time of primary THA in a population-based study comparing a THA-exposed cohort to an age-, sex- and residency-matched, unexposed cohort, with adjustment for the confounders comorbidity and socioeconomic background. 


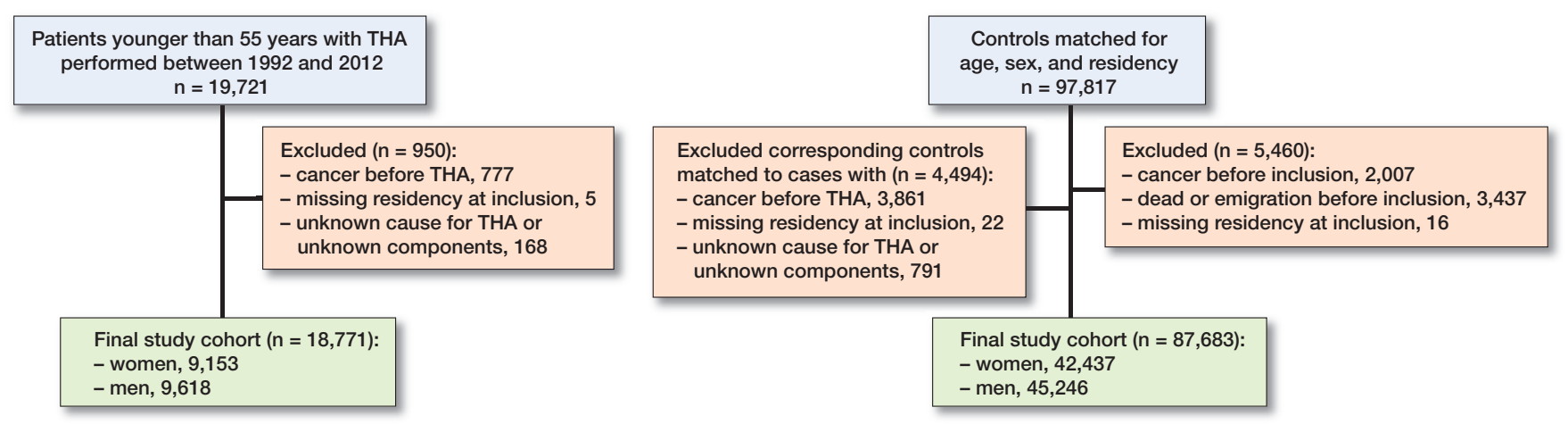

Figure 1. Flow chart describing the selection process underlying the final study population.

\section{Patients and methods}

\section{Study design and study population}

Swedish Hip Arthroplasty Register

The Swedish Hip Arthroplasty Register was established in 1979, but only from 1992 were implant data linked to the patient's individual identification number (PIN). Participants who received at least 1 THA at an age below 55 years between 1992 and 2012 were identified through their PIN in the Swedish Hip Arthroplasty Register. Patients with a THA were grouped by bearing type into those with conventional and those with metal-on-metal bearings (classical resurfacings or stemmed, large metal head THA included). The conventional bearing types included metal-on-polyethylene, which, in accordance with Swedish practice, represented the overwhelming majority of conventional bearings, followed by some ceramic-onpolyethylene and ceramic-on-ceramic bearings. The cohort of THA patients with conventional bearing THA was secondarily subdivided by fixation type into cemented, uncemented, and hybrid fixations, with the latter category comprising both classical and inverse hybrids.

\section{Statistics Sweden}

Statistics Sweden provided the control cohort for the individuals exposed to THA. Each was matched by age, sex, and place of residence to 5 unexposed individuals from the general population. Unexposed individuals had to be alive at the date of the first THA surgery of their respective case, the index date. The matching variables (age, sex, and region of residence) were considered appropriate to ensure an equal distribution among the exposed und unexposed individuals (20). Region of residence at time at surgery was matched to ensure that environmental factors that could be associated with cancer incidence did not confound the estimates. Age-matching was performed by year of birth; thus some unexposed individuals had died prior to the index date of their respective case and were excluded (Figure 1). Individuals not exposed to a THA at the index date could undergo THA surgery at a later time point, and such individuals ( $0.3 \%$ of the unexposed cohort) were censored at the date of their first THA surgery.
Statistics Sweden also provided information on personal incomes, subdivided into 4 categories along quartiles, and levels of education of the entire cohort. Level of education was separated into 4 categories: a base category including either no school education, less than 9 years of school, or an unknown level of education; this was followed by the 3 categories minimum 9 years of school education, high school education, or university education.

\section{Swedish Cancer Registry}

We obtained cancer diagnoses, but disregarded non-melanoma skin cancers and carcinoma in situ, on all participants from the Swedish Cancer Registry, with cancers defined along established main categories (Table 1, see Supplementary data). Participants who had a cancer diagnosis prior to the index date were excluded from the analyses. Registration of a first cancer diagnosis after the index date defined the occurrence of cancer. Time between the index date and the date at which this cancer diagnosis was registered defined the time to onset of the first cancer. When participants suffered from several cancers, we used the time to the occurrence of the first cancer to calculate the risk of developing "any" cancer. Subsequent new cancer forms occurring after the first cancer were used only for the estimation of the risk of developing this specific cancer form.

\section{Swedish Population Register}

The Swedish Population Register provided information on age, sex, death, and emigration on all participants. Comorbidities were assessed by collecting diagnosis codes on all participants from the Swedish National Patient Registry (ICD versions 9 and 10) and calculating the Charlson comorbidity index modified by Quan (21). The Charlson comorbidity index was categorized into 3 levels: 0: absence of comorbidities, 1-2: mild comorbidities, and $>2$ : severe comorbidities.

\section{Observation time}

Follow-up started on the index date and ended on the day of death, emigration, censoring, or December 31, 2012, whichever came first. The registers used as sources of our data are previously described and validated (22-24). 


\section{Characteristics of study population}

Linking register information on the selected individuals based on their individual PIN enabled us to select a final study population consisting of 18,771 individuals exposed to a THA with a median follow-up time of 7.9 years, and 87,683 matched, unexposed individuals with a median follow-up time of 8.1 years. Mean age was 47 years (SD 7; Table 2, see Supplementary data). The exposed individuals were considerably more comorbid than the unexposed, with $87 \%$ of exposed individuals having a Charlson comorbidity index $=0$, as compared with $98 \%$ among the unexposed. The level of education was lower among the exposed while income distributions were similar in both groups (Table 2, see Supplementary data).

Among the exposed, conventional bearings were used in the vast majority, whereas metal-on-metal devices were inserted in $8 \%$ of all exposed individuals. The most common type of implant fixation among conventional bearing THAs was cementless, followed by entirely cemented and hybrid or inverse hybrid fixation (Table 3, see Supplementary data). The most common diagnosis underlying THA surgery among the exposed was primary OA $(71 \%)$, followed by sequelae after pediatric hip disorders (12\%; Table 3, see Supplementary data).

\section{Statistics}

Continuous data were described using means, medians, minima, maxima, and standard deviations, as appropriate, and differences between observed and expected counts of categorical data were investigated by the Chi-square test. Cumulative cancer incidences were defined as the number of incident cancers per 100,000 person years. Cox multivariable regression models were fitted to calculate hazard ratios (HR) with 95\% confidence intervals (CI), either unadjusted or adjusted for the matching variables age, sex, and region of residence, and for the confounders Charlson comorbidity index, personal income, and level of education. We adjusted also for matching variables (age groups, sex, and region of residence at time of surgery) to avoid bias in the presence of the additional confounders $(25,26)$. Because we have a large population with access to the Swedish Population Register, the number of matching variables is not a limitation in finding appropriate controls, which otherwise can be a disadvantage of matching (25). The assumption of proportionality of hazards was investigated by plotting unadjusted cumulative incidence curves for each specific cancer and for each covariate for exposed and unexposed individuals, and by calculating Schoenfeld residuals. A major deviation from the assumption of proportionality was found for the covariate sex, therefore all further analyses were stratified by this variable. The matching variable "place of residence" contained $>300$ levels and was therefore included in the analyses as a stratum variable. Within the exposed cohort, 5,567 individuals received a second, contralateral THA at a later stage. These individuals were analyzed without consideration for subject dependency $(27,28)$.
The primary outcome was defined as the occurrence of any cancer after THA surgery. For secondary outcomes, the adjusted risk of cancer was stratified by the diagnoses underlying surgery or by the type of bearing in separate analyses. In order to analyze the adjusted risk of cancer in the entire population not stratified by sex we performed an additional sensitivity analysis for females and males grouped together, but with "sex" as a stratum variable in order not to violate the assumption of proportional hazards.

The level of significance was set at $\mathrm{p}<0.05$ in all analyses. R software (R version 3.6.3 (2020-02-29); R Foundation for Statistical Computing, Vienna, Austria) was used.

\section{Sensitivity analyses}

The question of whether exposure to large metal-on-metal bearings confers an increased cancer risk has been debated, and we therefore undertook a sensitivity analysis excluding individuals with metal-on-metal devices. We estimated the adjusted risk of developing cancer for the individuals exposed to THA compared with their matched unexposed individuals after excluding all individuals who were exposed to large metal-on-metal bearings, together with their respective unexposed cohort.

The exposure to THA might not confer an immediately enhanced risk for cancer, and we therefore performed an additional sensitivity analysis investigating the risk of any cancer divided into different time periods after the index date $(0-1$, $1-5,5-10,>10$ years).

A final sensitivity analysis was performed on the entire population of males and females grouped together, but by using sex as a strata variable (command "strat" in function "cph" in R package "rms") in order not to violate the assumption of proportionality.

\section{Ethics, registration, data sharing plan, funding, and potential conflicts of interest}

Ethical approval for this study was obtained from the Regional Ethical Review Board in Gothenburg (2013: 36013). In Sweden, no individual written consent is required for collection of data in the registries mentioned above but in consistency with the Swedish Patient Data Law of 2009 and the Personal Data Act of 1998 everyone has the option to have collected data erased at any time.

We are restrained in sharing the underlying dataset as the study was approved on the grounds of ensuring the confidentiality of sensitive patient data, owing to national regulations. However, data can be obtained from the register authorities upon reasonable request.

This study was supported by a grant from the Swedish Research Council (VR 2018-02612) to NPH.

The funding source had no role in the design and conduct of the study; collection, management, analysis, and interpretation of the data; preparation, review, or approval of the manuscript; and decision to submit the manuscript for publication. 


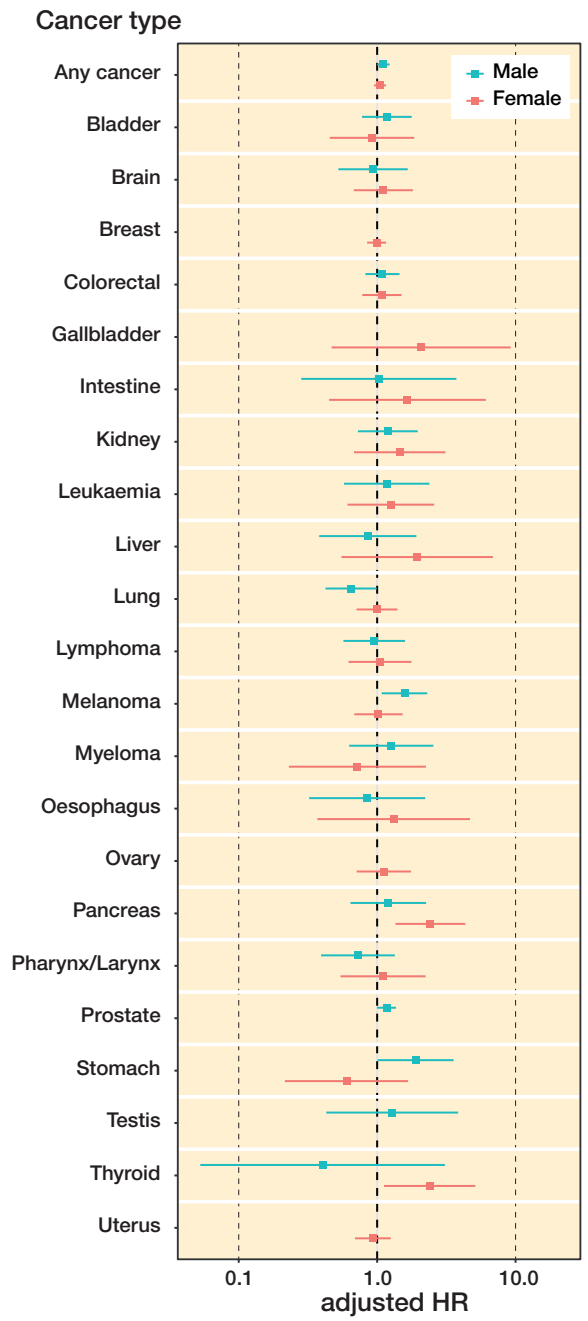

Figure 2. Forest plot of adjusted risk of developing any cancer and specific cancer stratified by sex.

All authors declared no potential conflicts of interest.

\section{Results}

\section{Cancer after THA}

5,227 incident cases of cancer occurred in the entire study population. Breast cancer was by far the most common cancer among females, as was prostate cancer among males, followed by colorectal cancer, cancers of the lung, and skin melanoma. The cumulative, unadjusted cancer incidence among exposed females was 625 incident cases per 100,000 person years, as compared with 579 incident cases per 100,000 person years among unexposed females, amounting to an HR of 1.1 (CI 0.95-1.2; Table 4, see Supplementary data) adjusted for age, sex, region, Charlson comorbidity index, education, and income. In exposed males, 584 incident cases of cancer per 100,000 person years occurred, whereas the corresponding number for unexposed males was 517. After adjustment for the same confounders, this resulted in an HR of 1.1 (CI 0.99-1.2) for exposed males.

When investigating specific cancer forms, exposure to THA in females was associated with a statistically increased adjusted risk of developing 2 specific cancer forms, pancreatic (HR 2.4; CI 1.4-4.3) and thyroid (HR 2.4; CI 1.1- 5.1) cancer (Figure 2, Table 4, see Supplementary data). The adjusted risk of developing leukemia was slightly elevated in females, whereas their adjusted risk of developing myeloma was attenuated, but none of these risk modifications was statistically significant. Exposed males had a statistically significantly increased adjusted risk for cancer of the stomach (HR 1.9; CI 1.0-3.6), skin melanoma (HR 1.6; CI 1.1-2.3), and prostate cancer (HR 1.2; CI 1.0-1.4; Figure 2, Table 5, see Supplementary data). The adjusted risk of developing leukemia or myeloma was slightly increased in exposed males, but none of these risk modifications were statistically significant.

Different indications for THA are associated with different comorbidity patterns that could have an impact on the risk of developing cancer, and we therefore investigated the risk of cancer stratified by the diagnoses underlying surgery. Females exposed to a THA due to avascular necrosis of the femoral head had an increased adjusted risk of developing any cancer (HR 1.8, CI 1.1-2.9). Also, males had an increased adjusted risk with the same underlying hip disease, but this finding was not statistically significant (adjusted HR 1.3, CI 0.8-2.0). Males who received their THA due to a fracture of the femoral neck had an increased adjusted risk of cancer (HR 1.9, CI 1.1-3.2). In females who received THA due to fracture, the adjusted risk was not statistically significantly elevated (HR 1.2, CI 0.7-2.0). Patients who received their THA due to primary osteoarthritis, secondary osteoarthritis, sequelae after pediatric hip diseases, or inflammatory joint disorders had some elevated adjusted risks of developing cancer, but none of these was statistically significant (Table 6, see Supplementary data).

In a similar pattern, we analyzed whether the type of THA fixation was associated with an increased cancer risk. This was the case in males who were exposed to cemented THA, in whom a slightly elevated adjusted risk of cancer (HR 1.2, CI 1.0-1.4) was found (Table 7, see Supplementary data).

\section{Sensitivity analyses}

In order to exclude a subgroup with a potentially enhanced cancer risk all individuals exposed to a large metal-on-metal bearings were excluded in a sensitivity analysis. The remaining females exposed to THA with conventional bearings $(\mathrm{n}=$ 8,784 ) had an adjusted risk of developing any cancer of 1.1 (CI 0.95-1.2), and the adjusted HR in males exposed to THA with conventional bearings was 1.1 (CI 0.99-1.2).

As the development of cancer after exposure to any carcinogenic agent may be expected to occur only after a certain period of exposure, we performed an additional sensitivity analysis by dividing the observation period after the index 
date into 4 time periods, estimating the risk of any cancer for each time period. This analysis revealed a slightly increased cancer risk only for males during the time period of 1 to 5 years after the exposure to THA (1.2, CI 1.0-1.5), Table 8), see Supplementary data.

We finally performed a sensitivity analysis for the entire study population of females and males grouped together, but by use of a stratum variable. In these analyses, we found no overall increased adjusted risk of cancer among the exposed individuals.

\section{Discussion}

\section{Principal findings}

Performing THA in patients younger than 55 years at the time of index surgery was not associated with an overall increased risk of cancer. We did, however, observe minor risk increases not quite reaching the threshold of statistical significance in males and in certain subgroups of exposed individuals. Exposed females had no overall increased risk of developing any cancer, but their risk of developing specific cancer types, i.e., pancreatic and thyroid cancer, was slightly and statistically significantly increased. Similarly, exposed males had no increased statistically increased adjusted risk of developing any cancer, but when we analyzed specific cancer types in exposed males stomach cancer, melanoma, and prostate cancer were cancer forms with a statistically significant risk increase. Large metal-on-metal bearings conferred no increased risk of overall cancer in this young population, but the investigated subgroup was small and estimation uncertainty large.

\section{Inherent strengths and limitations}

The main strengths of this study are its nationwide matched cohort design with a large number of individuals and, thus, a large number of incident cancers. Our access to comorbidities and socioeconomic data offers additional strengths because we were able to account for these potentially important confounders. Unfortunately, we lack information on body mass index (BMI), alcohol consumption, and smoking. We cannot rule out incompleteness and misclassifications in the underlying register data, but both the Swedish Hip Arthroplasty Registry and the Swedish Cancer registry are well-validated registers (22-24).

A longer follow-up than a median of 8 years would have been desirable, especially in this young cohort exposed to THA. However, individual patient data from the SHAR were available only from 1992, and younger patients were historically treated reluctantly with THA because of the uncertain long-term revision rates. This, together with the fact that the follow-up ended in 2012, limits our observation times. Even though ethical approval for the study was obtained in 2013, the administrative burden to coordinate the data-merge of the different registerers by ensuring data protection and the confi- dentiality of sensitive patient data was immense. This resulted in a delay of the delivery of the final database of 6 years. Bearing this in mind makes it even more important to report potential adverse effects such as risk of cancer in a younger cohort in order to prevent future patients from these risks.

The sample size of the entire exposed population seemed appropriate for the estimation of cancer risk, which is reflected by the narrow confidence intervals of the results. The sample sizes after stratification by type of bearing or by the underlying diagnoses for surgery are much smaller, with a corresponding decrease in precision and an increased risk of type-II errors. Nonetheless, following epidemiological methodology, we believed it important to explore cancer risks in selected subgroups of patients by performing such stratified analyses, always being aware of the limitations conferred by reduced sample sizes.

Methodologically, an observational study such as ours is open to many levels of confounding, and, also related to study design, we considered our study exploratory and performed no formal multiplicity adjustments. These issues must be remembered when interpreting risk estimates that may be inflated by residual confounding and muddled by type-I errors. In accordance with recommendations on studies with a matched cohort we adjusted for the matching variables $(25,26)$. However, as this approach has been debated, we performed a sensitivity analysis with adjustment only for the confounders socioeconomic background and comorbidity, but without adjusting for matching variables. This did not notably alter the risk estimates obtained.

It has been suggested that "fitter" individuals are selected for THA, leading to selection bias, which might attenuate cancer incidence among exposed individuals compared with the background population $(29,30)$. Contradicting this assumption, our analysis of comorbidities in exposed and unexposed individuals rather indicates the opposite, with more comorbidities present among young THA patients than among the general population. This finding is consistent with previous descriptions of cardiovascular and endocrine disorders being more common in patients with Legg-Calvé-Perthes' disease or slipped capital femoral epiphysis, 2 of the more frequent pediatric hip disorders (31-33). Thus, our estimated cancer risk would, rather, be inflated, which is consistent with a "worstcase" scenario. Detection bias could amplify the chances of the exposed cohort being diagnosed with cancer due to repeated contacts with healthcare related to the underlying hip disease. However, time spans from index surgery to the detection of various cancers were mostly between 5 and 10 years (data not shown), a time at which regular follow-up after THA has long ceased. We thus believe detection bias to be of minor importance. Another caveat is the issue of causality. The increased risk for some specific cancer forms might not be due to the THA procedure itself but rather to diagnoses underlying THA surgery or shared risk factors, such as obesity, which confers an increased risk for both cancer (34) and osteoarthritis (35). 


\section{Strengths and limitations in relation to other studies}

Our study included only individuals younger than 55 who have not been specifically addressed in other studies exploring the risk of cancer after THA. Our age selection was based on published research in the field, where 55 years seems broadly accepted as defining the upper age limit of "young" arthroplasty patients (36-39), but we are fully aware that this dichotomization is arbitrary, and other age limits would render different results. The hitherto largest observational study on cancer after THA includes 403,881 individuals, but the median age in the 3 subgroups of patients investigated in that study, divided by different types of THA, ranges from 55 to 70 years (40). The second largest cohort of 126,276 THA includes osteoarthritis patients with a mean age of 71 years (17), and the mean age in other studies on populations of similar sizes as that presented in our study is centered on $68-70$ years $(\mathbf{1 2}, \mathbf{1 8 , 4 1 - 4 3 )}$. Although even longer observation times would be desirable when investigating cancer risks in young individuals, a strength of our study is its median observation time of around 8 years, which is longer than in most other studies on the topic of cancer after THA. Only 2 other studies report similar observation times $(\mathbf{1 2 , 4 3 )}$, and only 1 has a longer observation time of 14 years (17).

Our study design with individuals exposed to a THA at the beginning of the study compared with unexposed individuals who may be exposed to a THA at a later time point resembles a prospective cohort study. All other studies on cancer after THA, except our previous study (17), either have no comparison group, or compare with individuals among whom no one was ever exposed to a THA, a scenario that is highly improbable in real life. Some previous studies compare cancer incidences in cohorts exposed to THA populations with a standardized incidence ratio $(12,16,41)$ a measure that has its strengths while on the other hand opening up for selection bias, as patients scheduled for THA deviate from the general population in terms of comorbidity, mortality, and socioeconomic factors $(29,44)$. Several previous studies on the topic of cancer after THA had no access to the important confounders of comorbidity and socioeconomic background, both of which are associated with the overall risk of cancer and the development of specific cancer forms $(45,46)$.

Due to the restrictive use of large metal-on-metal bearings in Sweden the subgroup of individuals exposed to this type of bearing is small in our study, whereas other investigators have

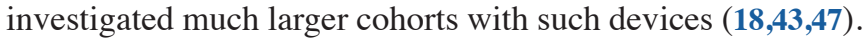
We concede that our cohort contains some individuals with small diameter metal-on-metal bearings. Such devices, for instance the "Metasul" bearing, became popular around the turn of the century, but they generate much lower concentrations of cobalt, chromium, and nickel than large diameter metal-on-metal bearings $(6,48)$, and their use was restricted to very limited numbers of patients (49). We cannot reconstruct their exact number in our database, but based on a detailed analysis of the cup types used in our cohort we estimate that less than $3 \%$ of our exposed individuals received such small diameter metal-on-metal bearings, and therefore believe this parameter has only limited influence.

\section{Accord and discord with other studies}

We find an about equal risk of cancer in younger patients exposed to THA when related to a sample from a comparable population, which is in agreement with previous studies on older populations $(\mathbf{1 7 , 1 8 , 4 0 )}$. The increased melanoma risk in exposed males confirms data from a meta-analysis in which a 1.4-fold risk of developing melanoma was described for arthroplasty patients, though of higher mean age $(\mathbf{1 4 , 1 6 )}$. The increased risk of prostate cancer in exposed males agrees with previous studies that describe risk increases of similar magnitudes $(12,15)$. These findings - such as an increased risk of thyroid cancer in females-may reflect that the exposed individuals are on average more likely to seek healthcare, a diagnostic bias not fully adjusted for by introducing socioeconomic status and educational level into the analysis. To our knowledge, our findings of increased risks of developing cancer of the stomach in exposed males and pancreatic cancer in exposed females are novel, but, given the large number of risk estimates and the limited study population these findings could represent type-I errors. Nonetheless, these observations may be linked to the exposure of younger individuals to potentially cancerogenic derivatives of THA, but further studies on young THA patients need to replicate these findings before conclusions can be drawn.

\section{Conclusions}

Some previous reports indicate an increased risk of cancer after THA, but this has been contradicted by others. None of the previous studies on the risk of cancer after THA specifically investigated younger cohorts, although younger patients are exposed to their implants for longer periods of time. In this first large-scale investigation on the risk of cancer after THA in young patients we find similar overall risk of cancer compared with individuals without THA exposure after adjustment for comorbidities and socioeconomic background. Within the limitations of our study, we believe that THA surgery can be considered a safe procedure regarding early cancer risk even in younger patients, a reassuring finding that can be communicated during preoperative counselling. Whether the risk of cancer is enhanced after longer exposure to THA remains to be investigated further.

NPH and JK designed the study and obtained ethical approval and access to the data. NE constructed the database and YDH and NPH conducted the data analysis with the help of Eva Freyhult. YDH and NPH drafted the initial version of the manuscript. All authors contributed to the interpretation of the data and critically revised the manuscript. All authors had full access to the data in the study and take responsibility for the integrity of the data and the accuracy of the data analysis. YDH is the guarantor. The corresponding author attests that all listed authors meet authorship criteria. 
The authors gratefully acknowledge the statistical help and review of the data analysis by Eva Freyhult.

Acta thanks Michael Mørk Petersen and Bart G Pijls for help with peer review of this study.

1. Gillespie W J, Frampton C M, Henderson R J, Ryan P M. The incidence of cancer following total hip replacement. J Bone Joint Surg Br 1988; 70: 539-42.

2. Meyskens F Jr. Cancer following total joint arthroplasty. Cancer Epidemiol Biomarkers Prev 2007; 16: 356.

3. Onega T, Baron J, MacKenzie T. Cancer after total joint arthroplasty: a meta-analysis. Cancer Epidemiol Biomarkers Prev 2006; 15: 1532-7.

4. Sunderman F W Jr, Hopfer S M, Swift T, Rezuke W N, Ziebka L, Highman P, et al. Cobalt, chromium, and nickel concentrations in body fluids of patients with porous-coated knee or hip prostheses. J Orthop Res 1989; 7: 307-15.

5. Davies A P, Willert H G, Campbell PA, Learmonth I D, Case C P. An unusual lymphocytic perivascular infiltration in tissues around contemporary metal-on-metal joint replacements. J Bone Joint Surg Am 2005; 87: 18-27.

6. Dahlstrand H, Stark A, Anissian L, Hailer N P. Elevated serum concentrations of cobalt, chromium, nickel, and manganese after metalon-metal alloarthroplasty of the hip: a prospective randomized study. $\mathrm{J}$ Arthroplasty 2009; 24: 837-45.

7. Langton D J, Sidaginamale R P, Joyce T J, Natu S, Blain P, Jefferson R D, et al. The clinical implications of elevated blood metal ion concentrations in asymptomatic patients with MoM hip resurfacings: a cohort study. BMJ Open 2013; 3.

8. Hailer N P, Bengtsson M, Lundberg C, Milbrink J. High metal ion levels after use of the ASR device correlate with development of pseudotumors and T cell activation. Clin Orthop Relat Res 2014; 472: 953-61.

9. Case C P, Langkamer V G, Howell R T, Webb J, Standen G, Palmer M, et al. Preliminary observations on possible premalignant changes in bone marrow adjacent to worn total hip arthroplasty implants. Clin Orthop Relat Res 1996: S269-S279.

10. Doherty A T, Howell R T, Ellis L A, Bisbinas I, Learmonth I D, Newson R, et al. Increased chromosome translocations and aneuploidy in peripheral blood lymphocytes of patients having revision arthroplasty of the hip. J Bone Joint Surg Br 2001; 83: 1075-81.

11. Paavolainen P, Pukkala E, Pulkkinen P, Visuri T. Cancer incidence in Finnish hip replacement patients from 1980 to 1995: a nationwide cohort study involving 31,651 patients. J Arthroplasty 1999: 272-80.

12. Brewster D H, Stockton D L, Reekie A, Ashcroft G P, Howie C R, Porter D E, et al. Risk of cancer following primary total hip replacement or primary resurfacing arthroplasty of the hip: a retrospective cohort study in Scotland. Br J Cancer 2013: 1883-90.

13. Nyren O, McLaughlin J K, Gridley G, Ekbom A, Johnell O, Fraumeni J F Jr, et al. Cancer risk after hip replacement with metal implants: a population-based cohort study in Sweden. J Natl Cancer Inst 1995; 87: 28-33.

14. Olsen J H, McLaughlin J K, Nyren O, Mellemkjaer L, Lipworth L, Blot W J, et al. Hip and knee implantations among patients with osteoarthritis and risk of cancer: a record-linkage study from Denmark. Int J Cancer1999: 719-22.

15. Visuri T, Pulkkinen $\mathbf{P}$, Paavolainen $\mathbf{P}$, Pukkala E. Cancer risk is not increased after conventional hip arthroplasty. Acta Orthop 2010; 81: $77-81$.

16. Visuri T, Pukkala E, Pulkkinen P, Paavolainen P. Decreased cancer risk in patients who have been operated on with total hip and knee arthroplasty for primary osteoarthrosis: a meta-analysis of 6 Nordic cohorts with 73,000 patients. Acta Orthop Scand 2003; 74: 351-60.
17. Hailer N P, Garland A, Gordon M, Kärrholm J, Sköldenberg O, Eriksson N, et al. No generally increased risk of cancer after total hip arthroplasty performed due to osteoarthritis. Int J Cancer 2020; 147 : 76-83.

18. Smith A J, Dieppe P, Porter M, Blom A W. Risk of cancer in first seven years after metal-on-metal hip replacement compared with other bearings and general population: linkage study between the National Joint Registry of England and Wales and hospital episode statistics. BMJ 2012; 344: e2383.

19. Mathiesen E B, Ahlbom A, Bermann G, Lindgren J U. Total hip replacement and cancer: a cohort study. J Bone Joint Surg Br 1995; 77: $345-50$.

20. de Graaf M A, Jager KJ , Zoccali C, Dekker F W. Matching, an appealing method to avoid confounding? Nephron Clin Pract 2011; 118: c31518

21. Quan H, Li B, Couris C M, Fushimi K, Graham P, Hider P, et al. Updating and validating the Charlson comorbidity index and score for risk adjustment in hospital discharge abstracts using data from 6 countries. Am J Epidemiol 2011; 173: 676-82.

22. Ludvigsson J F, Andersson E, Ekbom A, Feychting M, Kim J L, Reuterwall C, et al. External review and validation of the Swedish national inpatient register. BMC Public Health 2011; 11: 450.

23. Söderman P. On the validity of the results from the Swedish National Total Hip Arthroplasty register. Acta Orthop Scand Suppl 2000; 71: 1-33.

24. Pukkala E, Engholm G, Hojsgaard Schmidt L K, Storm H, Khan S, Lambe M, et al. Nordic cancer registries: an overview of their procedures and data comparability. Acta Oncol 2018; 57: 440-55.

25. Bland J M, Altman D G. Matching. BMJ 1994; 309: 1128.

26. Sjölander A, Greenland S. Ignoring the matching variables in cohort studies: when is it valid and why? Stat Med 2013; 32: 4696-708.

27. Bülow E, Nemes S, Rolfson $\mathbf{O}$. Are the first or the second hips of staged bilateral THAs more similar to unilateral procedures? A study from the Swedish Hip Arthroplasty Register. Clin Orthop Relat Res 2020; 478: 1262-70.

28. Robertsson $\mathbf{O}$, Ranstam J. No bias of ignored bilaterality when analysing the revision risk of knee prostheses: analysis of a population based sample of 44,590 patients with 55,298 knee prostheses from the national Swedish Knee Arthroplasty Register. BMC Musculoskelet Disord 2003; 4: 1.

29. Garland A, Gordon M, Garellick G, Kärrholm J, Sköldenberg O, Hailer N P. Risk of early mortality after cemented compared with cementless total hip arthroplasty: a nationwide matched cohort study. Bone Joint J 2017; 99-b: 37-43.

30. Cnudde P, Rolfson O, Timperley A J, Garland A, Kärrholm J, Garellick G, et al. Do patients live longer after THA and is the relative survival diagnosis-specific? Clin Orthop Relat Res 2018; 476(6): 1166-75. doi: 10.1007/s11999.0000000000000097.

31. Hailer Y D, Montgomery S M, Ekbom A, Nilsson O S, Bahmanyar S. Legg-Calve-Perthes disease and risks for cardiovascular diseases and blood diseases. Pediatrics 2010; 125: e1308-15.

32. Hailer Y D. Fate of patients with slipped capital femoral epiphysis (SCFE) in later life: risk of obesity, hypothyroidism, and death in 2,564 patients with SCFE compared with 25,638 controls. Acta Orthop 2020; 91: 457-43.

33. Wadström M G, Hailer N P, Hailer Y D. No increased mortality after total hip arthroplasty in patients with a history of pediatric hip disease: a matched, population-based cohort study on 4,043 patients. Acta Orthop 2021; 1-5. doi: 10.1080/17453674.2021.1963582

34. Lauby-Secretan B, Scoccianti C, Loomis D, Grosse Y, Bianchini F, Straif K. Body fatness and cancer: viewpoint of the IARC Working Group. N Engl J Med 2016; 375: 794-8.

35. Reyes C, Leyland K M, Peat G, Cooper C, Arden N K, Prieto-Alhambra $\mathrm{D}$. Association between overweight and obesity and risk of clinically diagnosed knee, hip, and hand osteoarthritis: a population-based cohort study. Arthritis Rheumatol 2016; 68: 1869-75. 
36. Aujla R S, Esler C N. Total knee arthroplasty for osteoarthritis in patients less than fifty-five years of age: a systematic review. J Arthroplasty 2017; 32: 2598-603.e2591.

37. Bayliss L E, Culliford D, Monk A P, Glyn-Jones S, Prieto-Alhambra D, Judge A, et al. The effect of patient age at intervention on risk of implant revision after total replacement of the hip or knee: a populationbased cohort study. Lancet 2017; 389: 1424-30.

38. Charette R S, Sloan M, DeAngelis R D, Lee G C. Higher rate of early revision following primary total knee arthroplasty in patients under age 55: a cautionary tale. J Arthroplasty 2019; 34: 2918-24.

39. Eskelinen A, Remes V, Helenius I, Pulkkinen P, Nevalainen J, Paavolainen P. Total hip arthroplasty for primary osteoarthrosis in younger patients in the Finnish arthroplasty register: 4,661 primary replacements followed for 0-22 years. Acta Orthop 2005; 76: 28-41.

40. Hunt L P, Blom A W, Matharu G S, Porter M L, Whitehouse M R. The risk of developing cancer following metal-on-metal hip replacement compared with non metal-on-metal hip bearings: findings from a prospective national registry "The National Joint Registry of England, Wales, Northern Ireland and the Isle of Man”. PLoS One 2018; 13: e0204356.

41. Mäkelä K T, Visuri T, Pulkkinen P, Eskelinen A, Remes V, Virolainen $\mathbf{P}$, et al. Risk of cancer with metal-on-metal hip replacements: population based study. BMJ 2012; 345: e4646.

42. Lalmohamed A, Vestergaard P, de Boer A, Leufkens H G, van Staa T
P, de Vries F. Changes in mortality patterns following total hip or knee arthroplasty over the past two decades: a nationwide cohort study. Arthritis Rheumatol 2014; 66: 311-18.

43. Ekman E, Laaksonen I, Eskelinen A, Pulkkinen P, Pukkala E, Mäkelä K. Midterm risk of cancer with metal-on-metal hip replacements not increased in a Finnish population. Acta Orthop 2018; 89(5): 575-9.

44. Gordon M, Rysinska A, Garland A, Rolfson O, Aspberg S, Eisler T, et al. Increased long-term cardiovascular risk after total hip arthroplasty: a nationwide cohort study. Medicine 2016; 95: e2662.

45. Mihor A, Tomsic S, Zagar T, Lokar K, Zadnik V. Socioeconomic inequalities in cancer incidence in Europe: a comprehensive review of population-based epidemiological studies. Radiol Oncol 2020; 54: 1-13.

46. Sarfati D, Koczwara B, Jackson C. The impact of comorbidity on cancer and its treatment. CA Cancer J Clin 2016; 66: 337-50.

47. Mäkelä K T, Visuri T, Pulkkinen P, Eskelinen A, Remes V, Virolainen $\mathbf{P}$, et al. Cancer incidence and cause-specific mortality in patients with metal-on-metal hip replacements in Finland. Acta Orthop 2014; 85: 32-8.

48. Dahlstrand H, Stark A, Wick M C, Anissian L, Hailer NP, Weiss R J. Comparison of metal ion concentrations and implant survival after total hip arthroplasty with metal-on-metal versus metal-on-polyethylene articulations. Acta Orthop 2017; 88: 490-5.

49. Swedish-Hip-Arthroplasty-Register. Annual Report; 2017.

\section{Supplementary data}

\section{Table 1. Coding of cancer diagnoses}

\begin{tabular}{|c|c|c|c|}
\hline Cancer & ICD7 & ICD9 & ICD-O/3 \\
\hline Bladder & 181 & $188.7-9$ & C67 \\
\hline \multirow[t]{2}{*}{ Brain, central nervous system } & 193 & 171 & C47 \\
\hline & 170 & $\begin{array}{l}191-2 \\
174\end{array}$ & $\begin{array}{l}\text { C70-2 } \\
\text { C50 }\end{array}$ \\
\hline Colon, rectum and anus & $153-4$ & 153 & C18-21 \\
\hline Gallbladder & 155.1 & 156 & C23.9 \\
\hline Hodgkin lymphoma & 201 & & \\
\hline Intestine & $152-4$ & $152-4$ & C17-21 \\
\hline Kidney & 180 & 189 & C64.9 \\
\hline Larynx & 161 & 161 & C32 \\
\hline Leukaemia & 204-7 & $204-8$ & C42 \\
\hline Lip, oral cavity and pharynx & $140-8$ & $140-9$ & $\mathrm{C} 00-14$ \\
\hline Liver & 155.0 & 155 & C22 \\
\hline \multirow[t]{2}{*}{ Lung } & $162-3$ & 162 & C33-34 \\
\hline & & 165 & $\begin{array}{l}\text { C38.4 } \\
\text { C80.9 }\end{array}$ \\
\hline Melanoma & 190 & 172 & $\mathrm{C} 44$ \\
\hline Multiple myeloma & 203 & 203 & C40-41 \\
\hline Nasopharynx & 146 & 147.9 & C11 \\
\hline \multirow[t]{2}{*}{ Non-Hodgkin lymphoma } & 200 & 200 & C85.9 \\
\hline & 202 & 202 & C44 \\
\hline Oesophagus & 150 & 150 & C15 \\
\hline Ovary & 175.0 & 183.0 & C56.9 \\
\hline \multirow[t]{2}{*}{ Pancreas } & 157 & $157.0-3$ & C25.0-3 \\
\hline & & $157.8-9$ & C25.8-9 \\
\hline Prostate & 177 & 185.9 & C61 \\
\hline Stomach & 151 & 151 & $\mathrm{C} 16$ \\
\hline Testis & 178 & 186.9 & C62 \\
\hline Thyroid & 194 & 193.9 & $\mathrm{C} 73$ \\
\hline \multirow[t]{3}{*}{ Uterus } & $171-2$ & 180.9 & C53 \\
\hline & 174 & $182.0-1$ & C54 \\
\hline & & 179.9 & C55 \\
\hline
\end{tabular}

Table 2. Characteristics of the study population. Values are count (\%) unless otherwise specified

\begin{tabular}{lrr}
\hline Factor & $\begin{array}{c}\text { Unexposed } \\
\mathrm{n}=87,683\end{array}$ & $\begin{array}{c}\text { Exposed } \\
\mathrm{n}=18,771\end{array}$ \\
\hline Female sex & $42,437(48)$ & $9,153(49)$ \\
Age, mean (SD) & $47.2(7.0)$ & $47.2(6.9)$ \\
Charlson comorbidity index & & \\
$\quad 0$ & $85,461(98)$ & $16,401(87)$ \\
$1-2$ & $2,021(2)$ & $2,202(12)$ \\
$>2$ & $201(0.2)$ & $168(0.9)$ \\
Education & & \\
None & $889(1.0)$ & $179(1.0)$ \\
9 years & $18,102(21)$ & $4,134(22)$ \\
High school & $41,709(48)$ & $9,323(50)$ \\
$\quad$ University & $26,835(31)$ & $5,107(27)$ \\
Personal income quarters & & \\
1st & $19,643(22)$ & $4,063(22)$ \\
2nd & $16,483(19)$ & $3,580(19)$ \\
3rd & $23,735(27)$ & $5,180(28)$ \\
4th & $27,674(32)$ & $5,920(32)$ \\
\hline
\end{tabular}


Table 3. Type of total hip arthroplasty (THA) divided by fixation and type of bearing, and underlying diagnosis for THA in 18,771 exposed individuals

\begin{tabular}{lr}
\hline Factor & $\mathrm{n}(\%)$ \\
\hline THA type & \\
Cemented & $6,269(33)$ \\
UncementeD & $6,589(35)$ \\
Hybrid & $4,445(24)$ \\
Metal-on-metal bearing & $1,468(7.8)$ \\
Underlying diagnosis & \\
Primary osteoarthritis & $13,250(71)$ \\
AVN & $946(5.0)$ \\
Fracture & $676(3.6)$ \\
Pediatric hip disease & $2,154(12)$ \\
Inflammatory joint disease & $1,537(8.2)$ \\
Secondary osteoarthritis & $208(1.1)$ \\
\hline
\end{tabular}

$\mathrm{AVN}=$ avascular necrosis of the femoral head.
Table 4. Risk of any cancer and specific cancers forms in exposed compared with unexposed females, adjusted for age, region of residence, comorbidities, and socioeconomic background

\begin{tabular}{|c|c|c|c|c|c|c|}
\hline $\begin{array}{l}\text { Females } \\
\text { Endpoint }\end{array}$ & & $\begin{array}{l}\text { posed } \\
\text { Incidence }\end{array}$ & $\begin{array}{l}\text { Une } \\
n\end{array}$ & $\begin{array}{l}\text { xposed } \\
\text { ncidence }\end{array}$ & $\begin{array}{l}\text { Crude } \\
\mathrm{HR}(\mathrm{Cl})\end{array}$ & $\begin{array}{l}\text { Adjusted } \\
\text { HR (Cl) }\end{array}$ \\
\hline Any cancer & 522 & 625 & 2,280 & 579 & $1.1(0.99-1.2)$ & $1.1(0.95-1.2)$ \\
\hline Bladder & 10 & 12 & 52 & 13 & $0.9(0.5-1.8)$ & $0.9(0.5-1.9)$ \\
\hline Brain & 22 & 26 & 89 & 22 & $1.2(0.7-1.9)$ & $1.1(0.7-1.8)$ \\
\hline Breast & 199 & 234 & 967 & 242 & $1.0(0.8-1.1)$ & $1.0(0.9-1.2)$ \\
\hline Colorectal & 49 & 57 & 207 & 51 & $1.1(0.2-1.5)$ & $1.1(0.8-1.5)$ \\
\hline Gallbladder & 3 & 4 & 6 & 2 & $2.4(0.6-9.5)$ & $2.1(0.5-9.2)$ \\
\hline Intestine & 5 & 6 & 9 & 2 & $2.6(0.9-7.9)$ & $1.7(0.5-6.1)$ \\
\hline Kidney & 9 & 11 & 31 & 8 & $1.4(0.7-2.9)$ & $1.5(0.7-3.1)$ \\
\hline Leukemia & 11 & 13 & 36 & 9 & $1.4(0.7-2.8)$ & $1.3(0.6-2.6)$ \\
\hline Liver & 4 & 5 & 8 & 2 & $2.4(0.7-7.8)$ & $1.9(0.6-6.9)$ \\
\hline Lung & 45 & 52 & 196 & 49 & $1.1(0.8-1.5)$ & $1.0(0.7-1.4)$ \\
\hline Lymphoma & 21 & 25 & 76 & 19 & $1.3(0.8-2.1)$ & $1.0(0.6-1.8)$ \\
\hline Melanoma & 31 & 36 & 146 & 36 & $1.0(0.7-1.5)$ & $1.0(0.7-1.5)$ \\
\hline Myeloma & 4 & 5 & 21 & 5 & $0.9(0.3-2.6)$ & $0.7(0.2-2.3)$ \\
\hline Esophagus & 3 & 4 & 12 & 3 & $1.2(0.3-4.2)$ & $1.3(0.4-4.7)$ \\
\hline Ovary & 25 & 29 & 105 & 26 & $1.1(0.7-1.7)$ & $1.1(0.7-1.8)$ \\
\hline Pancreas & 18 & 21 & 36 & 9 & $2.4(1.3-4.2)$ & $2.4(1.4-4.3)$ \\
\hline Pharynx/larynx & 12 & 14 & 40 & 10 & $1.4(0.7-2.7)$ & $1.1(0.5-2.2)$ \\
\hline Stomach & 5 & 6 & 30 & 7 & $0.8(0.3-2.0)$ & $0.6(0.2-1.7)$ \\
\hline Thyroid & 11 & 13 & 21 & 5 & $2.4(1.1-4.9)$ & $2.4(1.1-5.1)$ \\
\hline Uterus & 59 & 69 & 273 & 68 & $1.0(0.8-1.4)$ & $0.9(0.7-1.3)$ \\
\hline
\end{tabular}

$\mathrm{HR}(\mathrm{Cl})=$ Hazard ratio $(95 \%$ confidence interval).

Table 5. Risk of any cancer and specific cancers in exposed compared with unexposed males, adjusted for age, region of residence, comorbidities, and socioeconomic background

\begin{tabular}{lrrrrrr}
\hline $\begin{array}{l}\text { Males } \\
\text { Endpoint }\end{array}$ & \multicolumn{2}{c}{$\begin{array}{c}\text { Exposed } \\
\text { Incidence }\end{array}$} & $\begin{array}{r}\text { Unexposed } \\
\mathrm{n} \text { Incidence }\end{array}$ & $\begin{array}{c}\text { Crude } \\
\mathrm{HR}(\mathrm{Cl})\end{array}$ & $\begin{array}{c}\text { Adjusted } \\
\mathrm{HR}(\mathrm{Cl})\end{array}$ \\
\hline Any cancer & 461 & 584 & 1,964 & 517 & $1.2(1.0-1.3)$ & $1.1(0.99-1.2)$ \\
Bladder & 29 & 36 & 116 & 30 & $1.2(0.8-1.8)$ & $1.2(0.8-1.8)$ \\
Brain & 14 & 17 & 75 & 19 & $0.9(0.5-1.6)$ & $0.9(0.5-1.7)$ \\
Colorectal & 62 & 77 & 254 & 66 & $1.2(0.9-1.6)$ & $1.1(0.8-1.5)$ \\
Gallbladder & 1 & 1 & 0 & 0 & - & - \\
Intestine & 3 & 4 & 12 & 3 & $1.2(0.3-4.3)$ & $1.0(0.3-3.7)$ \\
Kidney & 21 & 26 & 77 & 20 & $1.3(0.8-2.2)$ & $1.2(0.7-2.0)$ \\
Leukemia & 10 & 12 & 39 & 10 & $1.2(0.6-2.5)$ & $1.2(0.6-2.4)$ \\
Liver & 8 & 10 & 35 & 9 & $1.1(0.5-2.4)$ & $0.9(0.4-1.9)$ \\
Lung & 26 & 32 & 169 & 44 & $0.8(0.5-1.1)$ & $0.7(0.4-1.0)$ \\
Lymphoma & 19 & 24 & 84 & 22 & $1.1(0.7-1.8)$ & $1.0(0.6-1.6)$ \\
Melanoma & 36 & 45 & 114 & 30 & $1.5(1.1-2.2)$ & $1.6(1.1-2.3)$ \\
Myeloma & 10 & 12 & 40 & 10 & $1.2(0.6-2.4)$ & $1.3(0.6-2.5)$ \\
Esophagus & 5 & 6 & 28 & 7 & $0.9(0.3-2.3)$ & $0.9(0.3-2.2)$ \\
Pancreas & 12 & 15 & 51 & 13 & $1.1(0.6-2.1)$ & $1.2(0.6-2.3)$ \\
Pharynx/larynx & 13 & 16 & 71 & 18 & $0.9(0.5-1.6)$ & $0.7(0.4-1.3)$ \\
Prostate & 193 & 242 & 813 & 212 & $1.2(0.99-1.4)$ & $1.2(0.99-1.4)$ \\
Stomach & 14 & 17 & 35 & 9 & $1.9(1.0-3.6)$ & $1.9(1.0-3.6)$ \\
Testis & 4 & 5 & 16 & 4 & $1.2(0.4-3.6)$ & $1.3(0.4-3.8)$ \\
Thyroid & 1 & 1 & 13 & 3 & $0.4(0.1-2.8)$ & $0.4(0.1-3.1)$ \\
\hline
\end{tabular}

$\mathrm{HR}(\mathrm{Cl})=$ Hazard ratio $(95 \%$ confidence interval $)$ 
Table 6. Risk of developing any cancer, separated by the underlying diagnosis for THA, stratified by sex and adjusted for age, region of residence, comorbidities, and socioeconomic background

\begin{tabular}{|c|c|c|c|c|c|c|}
\hline $\begin{array}{l}\text { Diagnosis } \\
\text { Sex }\end{array}$ & \multicolumn{2}{|c|}{$\begin{array}{l}\text { Exposed } \\
\mathrm{n} \quad \text { Incidence }\end{array}$} & \multicolumn{2}{|c|}{$\begin{array}{l}\text { Unexposed } \\
\text { n Incidence }\end{array}$} & \multirow[t]{2}{*}{$\begin{array}{l}\text { Crude } \\
\mathrm{HR}(\mathrm{Cl})\end{array}$} & \multirow[t]{2}{*}{$\begin{array}{l}\text { Adjusted } \\
\mathrm{HR}(\mathrm{Cl})\end{array}$} \\
\hline \multicolumn{5}{|c|}{ Primary osteoarthritis } & & \\
\hline Female & 347 & 679 & 1,470 & 619 & $1.1(0.98-1.2)$ & $1.1(0.96-1.2)$ \\
\hline Male & 347 & 598 & 1,514 & 551 & $1.1(0.97-1.2)$ & $1.1(0.95-1.2)$ \\
\hline \multicolumn{7}{|c|}{ Avascular necrosis of the femoral head } \\
\hline Female & 27 & 932 & 74 & 519 & $1.8(1.2-2.9)$ & $1.8(1.1-2.9)$ \\
\hline Male & 27 & 552 & 101 & 400 & $1.4(0.9-2.2)$ & $1.3(0.8-2.0)$ \\
\hline \multicolumn{7}{|l|}{ Fracture } \\
\hline Female & 24 & 789 & 95 & 608 & $1.3(0.9-2.1)$ & $1.2(0.7-2.0)$ \\
\hline Male & 22 & 763 & 73 & 453 & $1.8(1.1-2.9)$ & $1.9(1.1-3.2)$ \\
\hline \multicolumn{7}{|c|}{ Pediatric hip disease } \\
\hline Female & 57 & 440 & 306 & 503 & $0.9(0.7-1.2)$ & $0.9(0.7-1.1)$ \\
\hline Male & 22 & 391 & 98 & 370 & $1.1(0.7-1.7)$ & $1.0(0.6-1.6)$ \\
\hline \multicolumn{7}{|c|}{ Inflammatory joint disease } \\
\hline Female & 62 & 517 & 296 & 510 & $1.0(0.8-1.4)$ & $0.9(0.5-1.5)$ \\
\hline Male & 35 & 585 & 138 & 464 & $1.3(0.9-1.9)$ & $1.3(0.8-2.1)$ \\
\hline \multicolumn{7}{|c|}{ Secondary osteoarthritis } \\
\hline Female & 5 & 315 & 39 & 528 & $0.6(0.2-1.5)$ & $0.7(0.3-1.7)$ \\
\hline Male & 8 & 537 & 40 & 543 & $1.0(0.5-2.1)$ & $1.0(0.5-2.3)$ \\
\hline
\end{tabular}

$\mathrm{HR}(\mathrm{Cl})=$ Hazard ratio $(95 \%$ confidence interval)

Table 7. Risk of developing any cancer, separated by the type of total hip arthroplasty (THA), stratified by sex, adjusted for age, region of residence, comorbidities, and socioeconomic background

\begin{tabular}{|c|c|c|c|c|c|c|}
\hline \multirow{2}{*}{$\begin{array}{l}\text { THA type } \\
\text { Sex }\end{array}$} & \multicolumn{2}{|c|}{ Exposed } & \multicolumn{2}{|c|}{ Unexposed } & $\begin{array}{l}\text { Crude } \\
\mathrm{HR}(\mathrm{Cl})\end{array}$ & $\begin{array}{l}\text { Adjusted } \\
\mathrm{HR}(\mathrm{Cl})\end{array}$ \\
\hline & & & & & & \\
\hline Female & 253 & 665 & 1,137 & 630 & $1.1(0.9-1.2)$ & $1.0(0.9-1.2)$ \\
\hline Male & 213 & 689 & 870 & 568 & $1.2(1.1-1.4)$ & $1.2(1.0-1.4)$ \\
\hline \multicolumn{7}{|c|}{ Uncemented } \\
\hline Female & 126 & 551 & 535 & 502 & $1.1(0.9-1.3)$ & $1.1(0.9-1.3)$ \\
\hline Male & 114 & 493 & 506 & 465 & $1.1(0.9-1.3)$ & $1.0(0.8-1.3)$ \\
\hline \multicolumn{7}{|l|}{ Hybrid } \\
\hline Female & 132 & 645 & 559 & 580 & $1.1(0.9-1.4)$ & $1.1(0.9-1.3)$ \\
\hline Male & 116 & 589 & 519 & 551 & $1.1(0.9-1.3)$ & $1.0(0.9-1.3)$ \\
\hline \multicolumn{7}{|c|}{ Metal-on-metal bearing } \\
\hline Female & 11 & 499 & 49 & 489 & $1.0(0.5-2.0)$ & $1.0(0.5-1.8)$ \\
\hline Male & 18 & 347 & 69 & 288 & $1.2(0.7-2.0)$ & $1.3(0.7-2.1)$ \\
\hline
\end{tabular}

$\mathrm{HR}(\mathrm{Cl})=$ Hazard ratio $(95 \%$ confidence interval $)$

Table 8. Risk of any cancer for separate time periods after THA in the exposed compared with the unexposed, adjusted for age, region of residence, comorbidities, and socioeconomic background

\begin{tabular}{llrlrlll}
\hline $\begin{array}{l}\text { Years to } \\
\text { cancer Sex }\end{array}$ & \multicolumn{2}{c}{$\begin{array}{c}\text { Exposed } \\
\mathrm{n}\end{array}$} & \multicolumn{2}{c}{$\begin{array}{c}\text { Unexposed } \\
\mathrm{n} \text { Incidence }\end{array}$} & $\begin{array}{c}\text { Crude } \\
\mathrm{HR}(\mathrm{Cl})\end{array}$ & $\begin{array}{c}\text { Adjusted } \\
\mathrm{HR}(\mathrm{Cl})\end{array}$ \\
\hline $0-1$ & Female & 33 & 373 & 154 & 375 & $1.0(0.7-1.5)$ & $0.9(0.6-1.3)$ \\
& Male & 19 & 205 & 82 & 188 & $1.1(0.7-1.8)$ & $1.1(0.7-1.8)$ \\
$1-5$ & Female & 135 & 355 & 574 & 324 & $1.1(0.9-1.3)$ & $1.1(0.9-1.3)$ \\
& Male & 107 & 275 & 401 & 218 & $1.3(1.0-1.6)$ & $1.2(0.97-1.5)$ \\
$5-10$ & Female & 173 & 304 & 732 & 275 & $1.1(1.0-1.3)$ & $1.1(0.9-1.3)$ \\
& Male & 154 & 284 & 582 & 223 & $1.3(1.1-1.5)$ & $1.2(1.0-1.5)$ \\
$>10$ & Female & 180 & 304 & 819 & 290 & $1.1(0.9-1.3)$ & $1.1(0.9-1.3)$ \\
& Male & 181 & 361 & 899 & 362 & $1.0(0.9-1.2)$ & $1.0(0.9-1.2)$ \\
\hline
\end{tabular}

$\mathrm{HR}(\mathrm{Cl})=$ Hazard ratio $(95 \%$ confidence interval $)$ 